\title{
Cover art description
}

\section{Joseph Piven}

Published online: 8 October 2010

(C) Springer Science+Business Media, LLC 2010

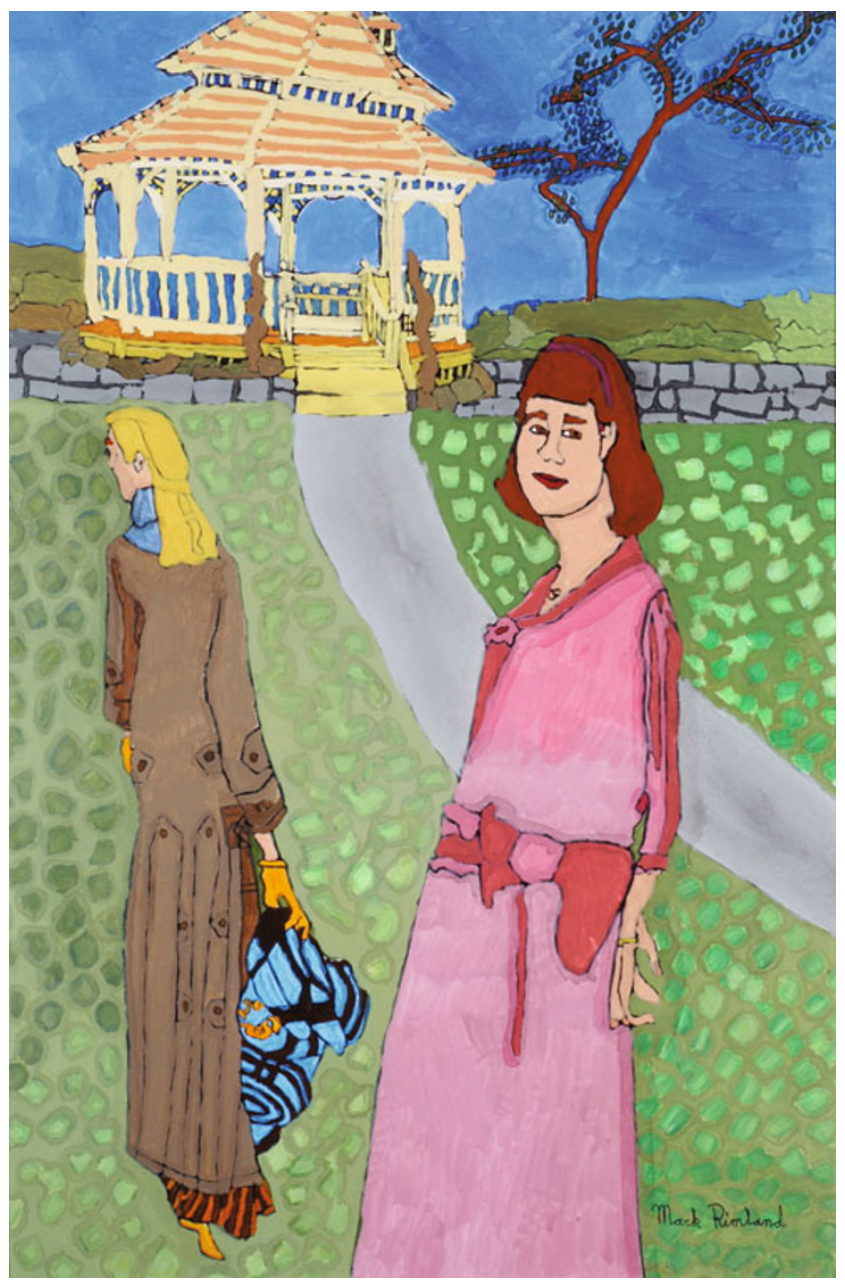

J. Piven $(\bowtie)$

Carolina Institute for Developmental Disabilities,

University of North Carolina,

Chapel Hill, NC 27599, USA

e-mail: jpiven@med.unc.edu
The cover image is a painting entitled "Gazebo" by artist Mark Rimland. This work is currently part of the MIND (Medical Investigation of Neurodevelopmental Disorders) Institute Collection at the University of California Davis. Born in 1956, Mr. Rimland resides in San Diego, California. He has been diagnosed with autism. Mr. Rimland has gained international acclaim for his work as both an artist and illustrator of children's books. 